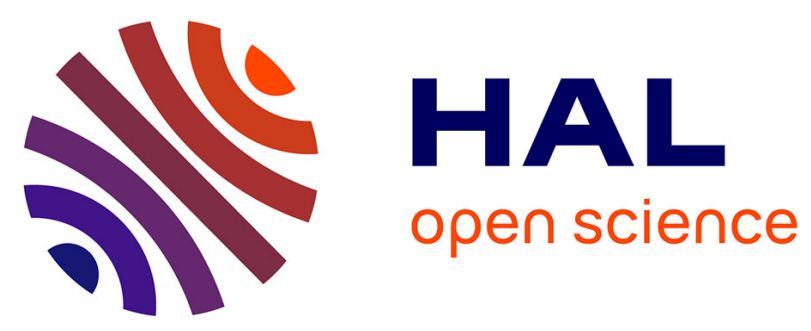

\title{
INVESTIGATION OF ELECTRICAL PROPERTY INHOMOGENEITIES FORMED BY PLASMA ETCHING
}

\author{
I. Bondarenko, S. Koveshnikov, E. Yakimov, N. Yarykin
}

\section{- To cite this version:}

I. Bondarenko, S. Koveshnikov, E. Yakimov, N. Yarykin. INVESTIGATION OF ELECTRICAL PROPERTY INHOMOGENEITIES FORMED BY PLASMA ETCHING. Journal de Physique IV Proceedings, 1991, 01 (C6), pp.C6-217-C6-222. 10.1051/jp4:1991633 . jpa-00250719

\section{HAL Id: jpa-00250719 https://hal.science/jpa-00250719}

Submitted on 1 Jan 1991

HAL is a multi-disciplinary open access archive for the deposit and dissemination of scientific research documents, whether they are published or not. The documents may come from teaching and research institutions in France or abroad, or from public or private research centers.
L'archive ouverte pluridisciplinaire HAL, est destinée au dépôt et à la diffusion de documents scientifiques de niveau recherche, publiés ou non, émanant des établissements d'enseignement et de recherche français ou étrangers, des laboratoires publics ou privés. 


\title{
INVESTIGATION OF ELECTRICAL PROPERTY INHOMOGENEITIES FORMED BY PLASMA ETCHING
}

\author{
I.E. BONDARENKO, S.V. KOVESHNIKOV, E.B. YAKIMOV and N.A. YARYKIN \\ Institute of Microelectronics Technology and High Purity Materials, USSR Academy of Sci- \\ ences, Chernogolovka, Moscow District 142432, USSR
}

\begin{abstract}
The possibility to use reactive ion etched $S_{i}$ crystals doped with gold as a model object for diffusion length profile reconstruction from the EBIC measurements has been discussed. It has been shown that the results of profile reconstruction from the EBIC measurements correlate well with the recombination center profiles obtained by DLTS.
\end{abstract}

1. Introduction

Electron beam induced current (EBIC) mode of the scanning electron microscope is now widely used for the local characterization of semiconductor structures [1-4]. In the case of homogeneous materials a lot of methods were proposed for such measurements [2,5] but for nondestructive characterization of planar structures the most suitable is the method based on the measurements of the collected efficiency dependence on electron beam energy [6,7]. In many cases the minority carrier diffusion length is inhomogeneous in depth and for reconstruction of its distribution it is necessary to develop some special techniques. One of such method was proposed in [8]. This method is based on the EBIC collected efficiency measurements on the beveled samples as a function of a coordinate along the beveled surface and therefore it demands special preparation of the samples, i.e. it is not nondestructive one. To develop other EBIC techniques for the reconstruction of diffusion length profile it is necessary to have samples with known diffusion length distribution measured by other techniques. Such samples which have the distribution of deep level centers with characteristic length in the range $0.1-1 \mu \mathrm{m}$ can be produced by reactive ion etching of $S i$ [9] and GaAs [10]. In the present paper it has been shown that the plasma etched Si samples with diffusion length profiles characterized by DLTS can be used as a model object for the diffusion length reconstruction from the EBIC measurements. The diffusion length profile was obtained by fitting of the measured collected efficiency dependence on electron beam energy with calculated ones.

2. Experimental

The investigations were carried out on Fu n-type Si crystals doped with phosphorus up to a concentration of $4 \cdot 10^{14} \mathrm{~cm}^{-3}$. Some of them were additionally doped with gold to a concentration of 
$8 \cdot 10^{13} \mathrm{~cm}^{-3}$. Samples cut from these crystals were etched in RF (13.56 MHz) plasma of $\mathrm{SF}_{6}-\mathrm{O}_{2}$ mixture in the regime of reactive ion etching. The chamber pressure during etching was kept at $8 \cdot 10^{-3}$ Torr. Etching duration was 1-40 min. A self-bias voltage at $R F$ electrode did not exceed $600 \mathrm{~V}$. Temperature of samples placed on water-cooled electrode was less than $100^{\circ} \mathrm{C}$ even at the highest value of RF power density ( 1 W/ $\mathrm{cm}^{2}$ ) used. The EBIC and DLTS investigations were carried out on Schottky barriers produced by gold evaporation on the chemically prepolished surface of the samples. The standard scheme of the DLTS equipment with lock-in amplifier as a correlator [11] was used. Temperature scanning of the samples was carried out in the range from 77 to $300 \mathrm{~K}$. Deep level pxofiles were measured by changing applied voltage and using small filling pulse value. EBIC measurements were carried out on the etched as well as on untreated parts of crystals using electron beam energy in the range from 1 to $30 \mathrm{kV}$.

\section{Sample characterization}

It is well known that plasma etching of semiconductor crystals leads to the damage layer formation near their surface [12]. One of the main reason for the damaged layer formation is irradiation of the crystal surface by low energy ( $\leq 1$ keV) particles accelerated by plasma discharge. Intrinsic point defects created during plasma etching in this region have high enough diffusion coefficients and therefore can diffuse to rather long depth. Diffusion of point defects results in the vacancy related defect formation up to the depth of $10 \mathrm{\mu m}$ and stimulates in- and/or out-diffusion of metal impurities (Fig. 1) $[9,13]$. Vacancy related defect distribution measured by DLTS can be described as

$$
N(z)=N_{s} \exp \left(-z / z_{1}\right)
$$

where $N_{s}$ is the surface concentration and $z_{1}$ is the characteristic length $\left(z_{1} \sim 1 \mu \mathrm{m}\right)$. The similar distribution with the same $z_{1}$ has been obtained for impurities introduced into the crystals during plasma

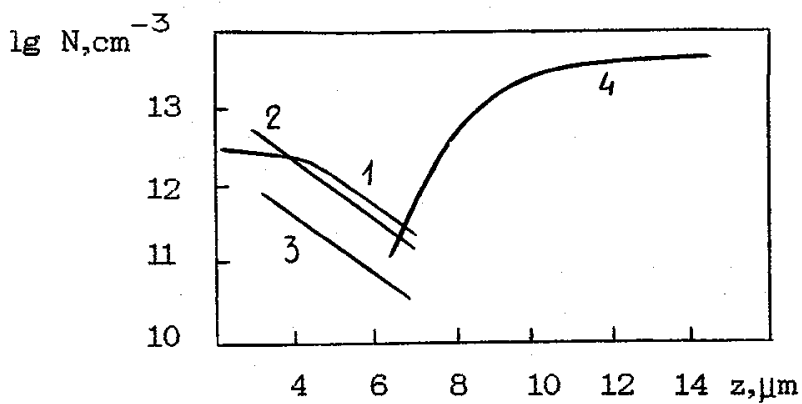

Fig.1 Profiles of vacancy-related complexes (1), in-diffused Au (2) and $\mathrm{Ni}$ (3) and out-diffused $\mathrm{Au}$ (4) in plasma etched Si. Etching duration is $5(4)$ and $10(1-3) \mathrm{min}$.

etching [13]. As it was shown in [13] for vacancies such dependence can be obtained by the solution of diffusion equation with a moving boundary. In this case the vacancy distribution can be describe as 


$$
N_{v}=N_{v O} \exp \left(-z / z_{v}\right)
$$

where $z_{v}=\left[\frac{R}{2 D_{v}}+\sqrt{\frac{R^{2}}{4 D_{v}^{2}}+\frac{1}{D_{v} \tau_{v}}}\right]^{-1}, D_{v}$ and $\tau_{v}$ are the diffusion coefficient and lifetime of vacancies, respectively, $R$ is the etching rate, $N_{v}$ and $N_{v o}$ are bulk and surface vacancy concentration, respectively. The coincidence the profiles obtained allows to associated enhanced metal diffusion with vacancy flow [9].

Plasma etching of $\mathrm{Si}$ doped with gold leads to out-diffusion of gold, the gettering depth being depended on etching duration $[9,13]$. The gold profile obtained can be described as

$$
\mathrm{N}_{\mathrm{Au}}=\mathrm{N}_{\mathrm{AuO}}\left[1+\mathrm{Bexp}\left(-\mathrm{z} / \mathrm{z}_{\mathrm{O}}\right)\right]^{-1}
$$

where $\mathrm{N}_{\mathrm{AU}}$ and $\mathrm{N}_{\mathrm{AuO}}$ are gold concentrations near the surface and in balk, respectively, $B$ and $z_{0}$ are some parameters which depend on etching conditions. To describe such profiles it was proposed [13] that in- and out-diffusion observed was stimulated by vacancies created during plasma etching. The numerical solution of the equation describing this process gives the profiles which correlate with experimental ones. The characteristic length of profiles obtained is about $1 \mu \mathrm{m}$ therefore such samples are very suitable for the EBIC characterization.

\section{EBIC investigations}

The EBIC image of the sample doped with gold the part of which is reactive-ion etched is presented in Fig.2. It is easy to see that

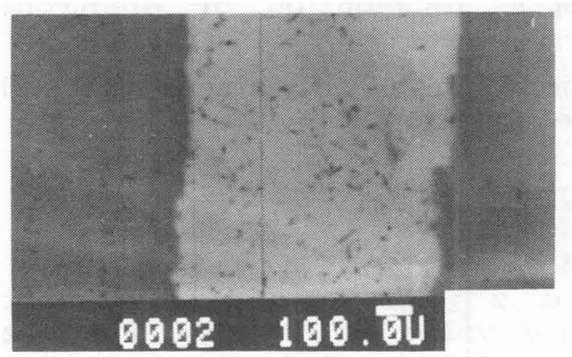

Fig.2. The EBIC image of the plasma etched $\mathrm{Si}\left(\mathrm{E}_{\mathrm{b}}=25 \mathrm{kV}\right)$. The treated part is the brighter one.

in accordance with DLTS data plasma etching increases the collected current. It should be mentioned that the image presented was obtained on the Schottky barriers, the surface of which was chemically polished before metal evaporation. In other case the collected current is very small. In our opinion it is associated with a thin highly damaged layer formation near the surface which can produce the barrier for minority carriers or essentially increase the recombination at the surface. The dependences of the collected efficiency on electron beam energy $E_{b}$ for the etched and untreated 
parts are presented in Fig.3. To obtain the parameters of the sample these dependences were compared with calculated ones. The collected efficiency $D$ was obtained as $D=I_{d} / e G_{0}$ where $G_{0}=E_{b} I_{b}\left(1-W^{2}\right) / e E{ }_{i}$, $\mathrm{I}_{\mathrm{b}}$ is the beam current, $e$ is the electronic charge, $E_{i}=3.6 \mathrm{eV}$ is the energy required for the formation of an electron-hole pair in $S i$, $x$ is the fraction of the electron beam energy lost due to

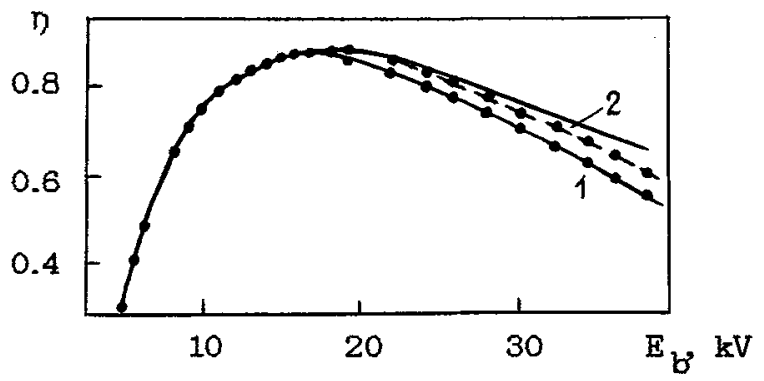

Fig.3. Dependence of the charge collection probability $\eta=I d / e G_{o}$ on $E_{b}$ for as-grown $\mathrm{Fz}-\mathrm{Si}<\mathrm{Au}>$ (1) and for the same crystal after plasma etching (2). The solid curves are calculated using (4) and (5) with L $=4.5$ and $8 \mu \mathrm{m}$, respectively. The dashed line is the best fitting using (6) with $B=26.3$ and $z_{0}=2.25 \mu \mathrm{m}$.

backscattered electrons. Collected current $I_{c}$ can be calculated in accordance with [14] as

$$
I=\int_{t_{m}}^{W} h(z) d z+\int_{w}^{\infty} h(z) \psi(z) d z
$$

where $h(z)$ is the depth distribution of electron-hole pair generation taken from [15], $W$ is the depletion region width, $t_{m}$ is the metal thickness, $\psi(z)$ is the charge collection probability and it can be obtained by solving the equation

$$
\nabla^{2} \psi(z)-\psi(z) / L^{2}(x)
$$

with boundary conditions $\psi(x, y, W)=1$ and $\psi \rightarrow 0$ for $z \rightarrow \infty$ and assuming that $\psi=1$ at $z \leq W$. For untreated samples we have obtained for the diffusion length value of $L=4.5 \mu \mathrm{m}$. But the dependence of $\eta$ on $\mathrm{E}_{\mathrm{b}}$ observed for plasma etched samples can not be described under the assumption about homogeneous diffusion length. The possibility to present the gold distribution in accordance with (3) in a parametric form allows to present the diffusion length distribution as

$$
\frac{1}{L^{2}(z)}=\frac{1}{L_{0}^{2}}+\frac{1}{L_{A U}^{2}}\left[1+B \exp \left(-z / z_{O}\right)\right]^{-1}
$$

where $L_{O}$ is the diffusion length in the same crystal but without gold, $\mathrm{L}_{\mathrm{Au}}$ is the diffusion length associated with gold. To increase the accuracy of the parameter determination we decrease the number of 
unknown parameters by the measurements of the untreated part of the same sample. From these measurements it is possible to obtain $W, L(\infty)$ and $t_{m}$ values. Plasma etching does not change the depletion region width [9] therefore, it is possible to use the parameters obtained for the untreated part of the sample for treated one. If it is not the case it is possible to change the bias applied to the Schottky barrier and increase a number of equations using the known relation between depletion region width and an applied bias. Numerical solution of (5) with $\mathrm{L}(\mathrm{z})$ taken from (6) and fitting the calculated curves with experimental one gives $L_{O}=9 \mu \mathrm{m}$ and for $B$ and $z_{O}$ the values which well correlates with those obtained from the DLTS measurements. The difference between the parameters obtained by the both techniques depends on the accuracy of measurements and in our investigations does not exceed $20 \%$.

It should be mentioned that the possibility to present the gold distribution in a parametric form allows us to present in a parametric form the diffusion length distribution. In this case it is possible to obtained unknown parameters of this distribution by solving the direct problem, i.e. by calculating the collected current using different values of parameters and obtained them by fitting the calculated curves with experimental one. This procedure is not so sensitive to the accuracy of measurements as the procedure of solving of inverse problem of diffusion length reconstruction from the EBIC measurements $[16,17]$.

\section{Conclusion}

Thus it has been shown that reactive ion etching of semiconductor crystals change the diffusion length in the subsurface layers. Si crystals after such treatment have a diffusion length profile with characteristic length in the $\mu \mathrm{m}$ range. These samples are very suitable as a model objects for diffusion length reconstruction from the EBIC measurements because it is possible to compare the results obtained with recombination center distribution measured by DLTS. The good correlation between the results obtained by these two techniques is observed.

\section{References}

1/ HANOKA J I, BELL R O, Ann -Rev Mater.Sci. 11 (1981) 353.

/2/ LEAMY H J, J.App l. Phys. 53 (1982) R51.

/3/ BRESSE J F, Scanning Electron Micrasc. IV (1982) 1487.

14/ HOLT D B, SEM Microcharacterization of Semiconductors. Ed.by D.B.Holt and D.C.Joy (Academ.Press), (1989) 241.

/5/ KITTLER M, SEIFERT W, Rev Phys.Appliq., Colloque C6, 24 (1989) C6-31.

16/ KAMM J D, Solid-State Electron. 19 (1976) 921.

17/ WU C J, WITTRY D B, J.Appl. Phys. 49 (1978) 2827.

/8/ DONOLATO C, KITTLER M, J.App l-PhYs. 63 (1988) 1569.

19 KOVESHNIKOV $S \mathrm{~V}$, YAKIMOV $E \mathrm{~B}$, YARYKIN $N A_{\text {; }}$ YUNKIN $V A_{\text {s }}$ Phys. Stat.Sol - (a) 111 (1989) 81 .

/10/ DUBONOS S V, KOVESHNIKOV S V, Phys.Stat.Sol. (a) 120 (1990) 77.

111/ MILLER G L, LANG D V, KIMERLING L C, Ann.rev.mater.7 (1977) 377. 
12/ PANG S W, Microelectronic Engineering 5 (1986) 351.

113/ KOVESHNIKOV $S \mathrm{~V}$, YAKIMOV E B, YARYKIN N A, YUNKIN V A, Defect control in semiconductors, ed.by K.Sumino, (North-Holland) (1990) 519 .

14/ DONOLATO C, App 1. Phys Lett. 46 (1985) 270.

15/ FITTING H-J, GLAEFEKE H, WILD W, Phys.Stat.Sol. (a)43 (1977) 185.

/16/ DONOLATO C Scanning Microse. 2 (1988) 801.

$117 /$ ZAITSEV S I, SAMSONOVICH A V IzV. AN SSSR, ser.Fiz. 54 (1990) 247 (In Russian). 